\title{
Regarding the Thermal Behaviour of a Centrifugal Pump for Oil Recovery
}

\author{
Adib Akhmetnabievich Gareev \\ Nizhnesortymskneft Oil/Gas Production Division, 12 Ulitsa Entuziastov, Nizhnesortymsky Settlement, Surgut Municipality, Tyumen Region, \\ Russia
}

Email address:

adibg@mail.ru

\section{To cite this article:}

Adib Akhmetnabievich Gareev. Regarding the Thermal Behaviour of a Centrifugal Pump for Oil Recovery. Engineering Science. Vol. 4, No. 2, 2019, pp. 28-33. doi: 10.11648/j.es.20190402.11

Received: May 15, 2019; Accepted: August 9, 2019; Published: September 17, 2019

\begin{abstract}
The modern world is characterized by increasing consumption of oil and its products. Oil production and consumption is an indicator of the economic level of development. However, there is a depletion of oil reserves in the field. New fields are not productive. Oil production in these fields leads to complications. Centrifugal pumps, which account for about $95 \%$ of the world's production, are particularly susceptible to such operational complications. Electric submersible pumps for oil well operation are the most flexible way, easily controlled and automated. Therefore, in low-productive fields, electric submersible pumps are widely used. However, in recent years, the operation of electric centrifugal pumps began to observe complications in the form of failures due to a decrease in the electrical resistance of the "cable - motor" system. Another complication in the operation of the electric centrifugal pump is a decrease in productivity. The third and most widespread complication is salt deposits in the inner cavity of the centrifugal pump. Studies conducted to identify the cause of salt deposition show that the original cause is the properties of reservoir water. However, it was not clear why salts were formed in some cases and not in others. The state of Affairs remained unclear until the investigation of the thermal condition of the electric submersible pump began. It turned out that the centrifugal pump when pumping strongly carbonated liquids rapidly reduce the efficiency. It has been shown that the pump temperature is determined by the properties of the formation fluid and the properties of the centrifugal pump. Salt deposition begins when formation water inside the pump begins to boil. Analytical expressions were obtained to calculate the pump temperature. It turned out that the temperature of the pump also depends on the coefficient of heat transfer from the metal to the gas-liquid mixture and the coefficient of thermal conductivity of the gas layer on the surface of the pump. This work is devoted to obtaining an analytical expression for determining the heat return coefficient. The ability to calculate the pump temperature and determine the boiling pressure of reservoir water at this temperature will predict the deposition of salts in the centrifugal pump.
\end{abstract}

Keywords: Electric Centrifugal Pump, Oil Production, Pump Dependence on Gas, Pump Heating, Salt Deposition in the Pump

\section{Introduction}

Many oil-producing companies recover oil using electric centrifugal pumps. The development of fields with low collecting properties, which has been taking place in work settlements over the last few years, creates a number of problems related to the application of these pumps in oil recovery. In the first place, oil fields with a low productivity factor are being increasingly developed using low-capacity units. Due to production problems in the depleted oil fields, low-capacity centrifugal pumps have the shortest mean time between overhauls, i.e. they are frequently under repair. Such fields create overheating problems for the electric cable lines and, over time, a deposition of salts inside the centrifugal pumps. The aforementioned overhaul problems of the low-capacity electric centrifugal pumps reduce the economic efficiency of the oil recovery. 


\section{Temperature Damage Points with Respect to Electric Motors}

Formerly, when oil recovery was performed using highcapacity centrifugal pumps, the thermal condition of the pumps were not about a matter of concern.

Therefore, the available studies on the thermal conditions of electric centrifugal pumps are purely theoretical. Greater importance was attached to investigations of the thermal conditions of electric motors as parts of the centrifugal pumps.

\section{Thermal Conditions of Centrifugal Pumps}

The broader application of low-capacity electric centrifugal pumps for oil recovery in fields with low collecting properties is leading to the appearance of a "complicated well stock". This well stock requires frequent repairs due to malfunctions of the electric centrifugal pumps; namely, this occurs as a result of cable line overheating and/or salt deposition. An increase of the cable line temperature (up to $230{ }^{\circ} \mathrm{C}$ ) leads to a snowballing growth of the failures caused by the deposition of salts. The current scientific research on the salt deposition in centrifugal pumps is based on the studies of Oddo and Thomas (1918-1930), while in Russia the authors of this work [15] are regarded as the main experts on this issue. However, there are many techniques for the determination of the brine solution saturation factor, which do not offer grounds for forecasting the salt deposition in centrifugal pumps. Such a paradoxical situation in oil recovery practices has emerged from the lack of a true theory in relation to centrifugal pump thermobaric conditions. The author of this article was the first to address the problem of low-capacity electric centrifugal pump thermobaric conditions as a function of the oil rheological parameters, the inflowing reservoir parameters and the centrifugal pump properties during the pumping of multiphase mixtures [7, 8].

\section{Thermobaric Conditions of Electric Centrifugal Pumps}

The findings that have been obtained on the dependency of the centrifugal pump thermobaric conditions on the formation of fluid properties (gas factors, producing a water cut, bubble-point pressure) and the centrifugal pump head and rate [4] are the result of patient investigations in the domain of multi-phase mixture heat conductivity theory.

1. On the basis of the obtained solution, a new "heat shock" phenomenon has been discovered - a process of an instantaneous and infinite rise of the pump temperature [6].

2. The case of "self-induced relaxation oscillations" (suction pressure, electric current value) has been studied [12].
3. Definitions of the optimal, permissible and maximum suction pressure of a centrifugal pump have been formulated [7].

4. A theoretical justification of the salt deposition phenomenon in centrifugal pumps has been provided [11].

5. The basis of forecasting the salt deposition and an operating practice without salt deposition have been described $[9,10]$.

6. Further investigations on the use of centrifugal pumps in oil recovery will lead to an overall automation of the pumping process.

The thermal condition of a centrifugal pump depend on the pump's performance factor, the gas content in the liquid-gas mixture, saturation pressure and the coefficient of the heat transfer from a pump to the pumped liquid-gas mixture. Thus, a study of the heat-transfer coefficient is important for developing a theory for the salt deposition forecasting of centrifugal pumps. Temperature rises (thermobaric condition) of electric centrifugal pumps as a function of the process duty cycles (pumping parameters, suction pressure, gas and water content, etc.) and the parameters of the pumped liquid-gas mixture can be considered by using the obtained formula [14], on the condition that a liquid-gas mixture is being pumped.

$$
\Delta T_{w}=T_{w}-T_{f}=\frac{\phi}{1-\phi} \frac{q_{0} P_{b} P_{i n} R_{2}}{2(1-B) h \Gamma P_{a}}\left\{\frac{1}{\alpha}+\frac{\delta_{t h}}{\lambda_{c}}\right\}
$$

where Tw is the temperature inside the pump housing, ${ }^{\circ} \mathrm{K}$; Tf is the temperature of the pumped liquid-gas mixture, ${ }^{\circ} \mathrm{K}$; R2 is the radius of the pump cylindrical housing, $\mathrm{m} ; P_{i n}$ is the pump inlet (suction) pressure, atm; $\mathrm{Pb}$ is the bubble-point pressure, atm; $\Gamma$ is the reservoir gas-oil ratio, $\mathrm{m} 3 / \mathrm{m} 3 ; \mathrm{h}$ is the pump head with free gas in the mixture, atm; $\delta_{t h}$ is the thickness of gas bubbles on the pump surface, $\mathrm{m}$; B is the produced water cut as a decimal fraction (less than 0.98 ); $\lambda_{c}$ is the gas blanket heat conductivity on the pump housing surface, $\mathrm{W} /\left(\mathrm{m}^{*} \mathrm{~K}\right) ; \quad \alpha$ is the convection heat transfer coefficient in the labyrinths of the pump elements with respect to the liquid-gas mixture, $\mathrm{W} /(\mathrm{m} 2 * \mathrm{~K}) ; q_{0}$ is the heat source power density, $\mathrm{W} / \mathrm{m}^{3}$; and $P_{a}$ is the atmospheric pressure, atm.

For the practical forecasting of the salt deposition in centrifugal pumps, the formula (1) demands further detailing - specifically, a definition of the calculation method for the parameters, participating in the heat formation and heat distribution processes is required. One of the influencing parameters is the convection heat transfer coefficient $\alpha$. The complexity of an analytic representation of this coefficient includes contributions from the liquid-gas mixture flow conditions in the labyrinths of the pump elements and a lack of sufficient knowledge about liquid-gas mixture properties under a relatively high suction pressure. 
The flow of a highly pressurised water-gas-oil mixture inside a centrifugal pump is a complex thermodynamic process, which currently remains unexplored (with the exception of certain studies involving models of air-oil mixtures at atmospheric pressure $[14,15])$.

Therefore, in order to simulate the process of a heat transfer from the metal surfaces of the centrifugal pump working components to the gas-liquid mixture, a number of assumptions must be made. In particular, let us assume the flow of a two-phase gas-liquid mixture in the labyrinths of the pump's working components, where the water-oil layer moves directly on the metal surface and the gas phase does not come into contact with the metal surfaces of the working components. In this case, in the coordinate system associated with the guide vanes, the flow of the water-oil mixture can be roughly described as a vortex motion (with constant changes of the flow rate and direction) (Figure 1).

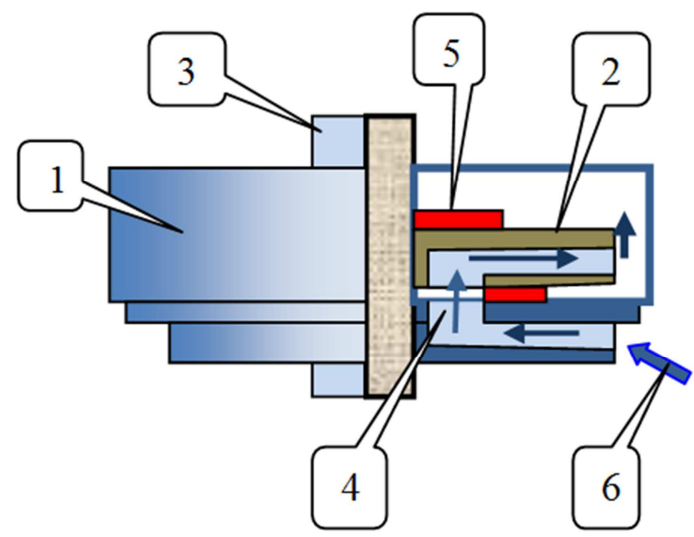

Figure 1. Section of a Centrifugal Pump Unit.

1 - guide vanes; 2 - impeller; 3 - pump shaft; 4 - gas-liquid mixture flow channels; 5 - journal bearing; 6 - direction of motion of the gas-liquid mixture.

Figure 1 shows a schematic representation of the working components of a centrifugal pump. The gas-liquid mixture enters the cavity of the guide vane (1), passes into the cavity of the impeller that rotates on the shaft (3) (at the standard frequency of $3000 \mathrm{rpm}$ ) and is then fed into the next guide vane. The kinetic energy of the gas-liquid mixture, acquired in the process of the rotation, is converted into the potential energy of compression. Friction (or heat generation) occurs between the journal bearing that is made of a composite epoxy material and the impeller hub. Since the thermal conductivity of the composite epoxy material $\left(\left(\lambda=0,23 \frac{W}{(m * K)}\right)\right.$ is insignificant (it is hundreds of times lower than the thermal conductivity of steel), the resulting amount of heat passes partially into the gas-liquid mixture, with the thermal properties of the latter largely depending on the availability of the associated (formation) water in the well production. The thermal conductivity of water is several times lower than that of any metal (approximately fourfold). Therefore, let us assume that around $50 \%$ of the heat is transferred to the gas-liquid mixture (based on the properties of the impeller, provided with cavities in the form of an irregular parallelepiped).
In the conditions at the level of the centrifugal pump, where the pressure varies from tens to several units of $\mathrm{MPa}$, the density of the water is constant (around $1 \mathrm{~g} / \mathrm{cm}^{3}$ ), the density of the oil varies from 0.9 to $0.6 \mathrm{~g} / \mathrm{cm}^{3}$, and the gas density is the lowest and does not exceed $0.06 \mathrm{~g} / \mathrm{cm}^{3}$. In our approximation, the formation of water always remains on the inner surface of the guide vane, followed by oil and gas, with the water moving in the impeller cavity along the lower generatrix. Let us assume that the oil and gas layers never touch the surface of the impeller cavity; that is, the heat exchange occurs from the metal to the water layer (or to the oil layer when water is not available). Since the working gap between the impeller and the internal cavity of the guide vane is $0.002 \mathrm{~m}$ and the radius of the impeller is $0.037 \mathrm{~m}$, with a gas-liquid mixture flow rate of $18 \mathrm{~m}^{3} /$ day (around 0.21 litres per second), an average flow rate of $0.46 \mathrm{~m} / \mathrm{s}$ may be calculated by dividing the volumetric flow rate by the area of the gap. The diameter of the conditional gap between the radius of the impeller and the radius of the inner surface of the guide vane is $0.0024 \mathrm{~m}$; the viscosity of the formation water is $v=0,656 * 10^{-6} \mathrm{~m}^{2} / \mathrm{s}$; and the Reynolds number is $\mathrm{R}=$ 4182 , i.e. the flow may be "conditionally" referred to as laminar (less than 4200). However, due to the nature of the flow, with constant changes in the flow direction and in the cross-sectional area of the flow (due to the mixing of the liquids), the boundary layer theory must be applied for the "turbulent flow" of the liquid in order to estimate the heat transfer coefficient $[14,16]$.

Indeed, according to the Prandtl hypothesis, the thickness of the boundary layer (liquid layer thickness) is significantly smaller than the overall dimensions of the working component (the impeller of a centrifugal pump). Then,

$$
\delta \ll l
$$

where $\delta$ is the thickness of the liquid layer; and $l$ is the typical impeller size.

Let us estimate the layer thickness $\delta$ of the boundary layer flow in the impeller. To do this, let us assume the rotation radius of $37 \mathrm{~mm}$ and the rotation rate of $50 \mathrm{rpm}$, with the liquid flow rate in the coordinate system associated with the impeller of:

$$
\delta \approx \frac{V \mathrm{c}}{2 \pi R \nabla \mathrm{x}}=\frac{0.21 * 10^{-3}}{2 * 3.14 * 0.037 * 0.005 * 50}=0.0036 \mathrm{~m}
$$

where $\mathrm{V}_{\mathrm{c}}$ is the volumetric flow rate of water; $\mathrm{R}$ is the radius of rotation of the impeller; and $\nabla \mathrm{x}$ is the height of the impeller cavity.

Under all the assumptions made, the thickness of the boundary layer is $0.0036(3.6 \mathrm{~mm})$, which is significantly smaller than the radius of the impeller that is equal to $37 \mathrm{~mm}$ (1).

By analogy with the Reynolds hypothesis [14], the Prandtl-Taylor formula is applicable for the heat transfer coefficient:

$$
\alpha=\frac{\sigma_{\mathrm{c}} * \mathrm{c}_{\mathrm{p}}}{v_{\infty}} \frac{1}{1+\frac{v_{W}}{v_{\infty}}(P r-1)}
$$


where $\alpha$ is the heat transfer coefficient; $\sigma_{\mathrm{c}}$ is the shear stress at the surface-liquid interface; $c_{p}$ is the specific heat capacity of water at a constant pressure; $v_{\infty}$ is the water flow rate at the inlet to the impeller; $v_{w}$ is the water flow rate in the gap between the rim of the guide vane and the impeller outlet; and $\mathrm{P}_{r}$ is the Prandtl number [14].

Formula (4) is notable, as it uses such quantities as the flow rate and heat capacity of the water. A similar formula may be compiled for the oil component of the gas-liquid mixture.

The graphic dependence for the Prandtl number is shown in Figure 2. At temperatures above $150{ }^{\circ} \mathrm{C}$, the value of the Prandtl number tends to unity.

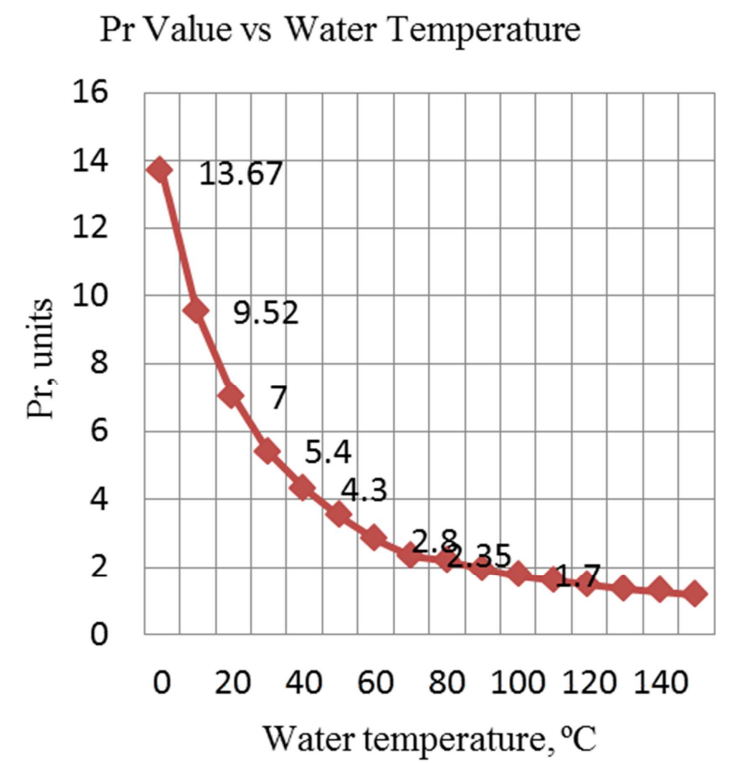

Figure 2. Pr Value vs Temperature.

Let us calculate the linear flow rate of the water layer depending on the change in the geometry of the internal cavity of the impeller when the ECP unit supply (discharge) rate is $18 \mathrm{~m}^{3} /$ day $\left(0.000208 \mathrm{~m}^{3} / \mathrm{s}\right)$.

The linear flow rate at the inlet of a centrifugal pump in a well with an internal diameter of $148 \mathrm{~mm}$ (production casing with a diameter of $168 \mathrm{~mm}$ ) is equal to:

$$
v_{\infty}=\frac{0.000208}{3.14 * 0.074^{2}}=0.0121 \frac{\mathrm{m}}{\mathrm{s}}
$$

The oil density is lower than the density of water by $15 \%$ to $25 \%$, and the thermal conductivity coefficient value for oil is half the water value. According to [14] and formula (4), let us substitute the water values with the oil values in the Prandtl-Taylor formula:

$$
\alpha=\frac{\sigma_{\mathrm{c}} * \mathrm{C}_{o i l}}{v_{\infty}} \frac{1}{1+\frac{v_{o i l}}{v_{\infty}}(\operatorname{Pr}-1)}
$$

where $\alpha$ is the heat transfer coefficient; $\sigma_{\mathrm{c}}$ is the shear stress at the surface-liquid interface; $\mathrm{C}_{\text {oil }}$ is the specific heat capacity of oil at a constant pressure; $v_{\infty}$ is the oil flow rate at the inlet to the impeller; $v_{\text {oil }}$ is the oil flow rate in the gap between the rim of the guide vane and the impeller outlet; and $\mathrm{P}_{r}$ is the Prandtl number.

The generalised formula for an oil-water-gas mixture, which is similar to (4), may be written as follows:

$$
\alpha_{m i}=\frac{\sigma_{m i} \mathrm{C}_{m i}}{v_{m i \infty}} \frac{1}{1+\frac{v_{m i}}{v_{m i \infty}}(\operatorname{Pr}-1)}
$$

where $\alpha_{m i}$ is the heat transfer coefficient of the mixture; $\mathrm{C}_{m i}$ is the specific heat capacity of the mixture; $v_{m i}$ is the mixture flow rate at the surface boundary; $v_{\text {mio }}$ is the mixture flow rate at a distance from the surface (for example, the average mixture flow rate at the inlet openings of the centrifugal pump); and $\sigma_{m i}$ is the shear stress of the mixture at the boundary with the flat surface. The $P_{r}$ number at high temperatures approaches unity; therefore, the value of this number is approximately equal to the $P_{r}$ number for water (considering that the heat capacity of oil is half the heat capacity of water, and that the heat capacity of the associated gas is ten times lower than the heat capacity of water) [13].

The heat capacity of the mixture is calculated by the formula:

$$
\mathrm{C}_{m i}=\left[\left(\mathrm{C}_{w} * \mathrm{~B}+\mathrm{C}_{o i l}(1-\mathrm{B})\right] *(1-\varphi)+C_{\Gamma} * \varphi\right.
$$

where $\varphi$ is the gas content, as a decimal quantity; B is the water cutting of the well production, as a decimal quantity: $\mathrm{C}_{\text {oil }}$ is the oil specific heat; and $\mathrm{C}_{w}$ is the water specific heat.

Since the specific heat capacity of the gas is much lower than the specific heat capacity of the oil (water) (at the pressures at the inlet of the centrifugal pump), the third term may be neglected. Then, equation (7) is simplified as follows:

$$
\mathrm{C}_{m i}=\left[\left(\mathrm{C}_{w} * \mathrm{~B}+\mathrm{C}_{o i l}(1-\mathrm{B})\right] *(1-\varphi)\right.
$$

The flow rate of the mixture is significantly influenced by two values: the flow rate of the well and the content of free gas in the mixture produced at the inlet of the centrifugal pump. Based on the equality of the volumetric flow rates of the mixture in any arbitrary cross-sectional area in the impeller through-passage of the centrifugal pump, it may be assumed that:

$$
v_{m i}=\frac{v_{m i \infty}}{S(1-\varphi)}
$$

According to the Reynolds hypothesis, with a turbulent flow, the processes of the heat and the momentum transfer [14] are similar, and therefore when the heated liquid interacts with the cold solid, the relative change in its "heat content" must be equal to the relative change in the momentum:

$$
\frac{q_{c}}{\rho v_{\infty} C_{p}\left(T_{\infty}-T_{c}\right)}=\frac{\sigma_{c}}{\rho v_{\infty}^{2}}
$$

where $v_{\infty}$ and $T_{\infty}$ are the approach flow parameters, i.e. the flow rate and temperature of the mixture at the pump inlet; and $T_{c}, q_{c}, \sigma_{\mathrm{c}}$ are the temperature values on the surface of the impeller, the heat flux density and the shear stress on the inner surface of the impeller, respectively.

Assuming that: 


$$
\sigma_{c}=c_{f} \frac{\rho_{m i} v_{m i \infty}^{2}}{2} q_{c}=\rho_{m i}\left(T_{\infty}-T_{c}\right)
$$

Substituting it into (6) from (11), we obtain:

$$
\begin{gathered}
\alpha_{m i}=\frac{C_{f} \frac{\rho_{m i} v_{m i \infty}^{2}}{2} C_{m i}}{v_{m i \infty}} \frac{1}{1+\frac{v_{m i}}{v_{m i \infty}}(\operatorname{Pr}-1)}= \\
c_{f} \frac{\rho v_{m i \infty} C_{m i}}{2} \frac{1}{1+\frac{v_{m i}}{v_{m i \infty}}(\operatorname{Pr}-1)}
\end{gathered}
$$

where $\mathrm{c}_{f}$ is the friction coefficient.

In the widest range of the $\mathrm{Re}$ variation, the friction coefficient may be calculated by the formula:

$$
\mathrm{c}_{f}=\left(0.87 \operatorname{LnR} e_{\mathrm{x}}-0.65\right)^{-2.3}
$$

where $R e_{x}$ is the Reynolds number calculated by the tangential velocity in the impeller channels of the centrifugal pump (flow rate). Using the formulas $(8,9,12,13)$, the heat transfer coefficient in the impellers may be calculated.
Let us provide a numerical example to illustrate the formula (12): calculate the mixture flow rate at the inlet to the impeller on the assumption that the flow rate will be increased proportional to the squared ratio of the radii. Thus, if $R_{\text {ext }}=71 \mathrm{~mm}$ and $R_{\text {int }}=30 \mathrm{~mm}$, the squared ratio of the outer radius to the inner radius will be equal to 5.56 .

The flow rate of the mixture, with the gas content of $\varphi=$ 0.7 , will be equal to:

$$
v_{m i}=0.0121 * 5.56 * \frac{1}{(1-0.7)}=0.24 \frac{\mathrm{m}}{\mathrm{s}}
$$

The density of the mixture may be determined as:

$$
\rho_{m i}=\left\{\rho_{o i l}(1-\mathrm{B})+\rho_{w} \mathrm{~B}\right\} *(1-\varphi)+\rho_{\Gamma} \varphi
$$

Let's assume that the oil density is $\rho_{\text {oil }}=758 \frac{\mathrm{kg}}{\mathrm{m}^{3}}$; water density is $\rho_{w}=1001 \frac{\mathrm{kg}}{\mathrm{m}^{3}}$; gas density is $\rho_{\Gamma}=234 \frac{\mathrm{kg}}{\mathrm{m}^{3}}$; gas content at the pump inlet is $\varphi=0.7$; and the produced water cut is $28 \%$.

Then, the mixture density will be equal to:

$$
\rho_{m i}=\{758(1-0.28)+1001 * 0.28\} *(1-0.7)+234 * 0.7=410.8 \frac{\mathrm{kg}}{\mathrm{m}^{3}} ;
$$

The heat capacity of the mixture may be determined by the concentrations of the components: water, oil and the associated gas (due to the mixing nature of the flow):

$$
\mathrm{C}_{m i}=\left[\mathrm{C}_{w} \mathrm{~B}+\mathrm{C}_{o i l}(1-\mathrm{B})\right](1-\varphi)+\mathrm{C}_{\Gamma} \varphi
$$

The water thermal capacity is $\mathrm{C}_{w}=4.128 \frac{\mathrm{kJ}}{\mathrm{kg*K}}$; oil

$$
\mathrm{C}_{m i}=[4.128 * 0.28+2.05 *(1-0.28)] *(1-0.7)+1 * 0.7=1,4938 \frac{\mathrm{kJ}}{\mathrm{kg} * \mathrm{~K}}
$$

The resistance coefficient is:

$$
\begin{gathered}
\mathrm{C}_{f}=(0.87 * \operatorname{Ln} 4282-0.65)^{-0.23}=(8.362-0.65)^{-0.23} \\
=7.71^{-0.23}=0.625
\end{gathered}
$$

Let us select the Prandtl number, assuming that the temperature in the process will be at least $150^{\circ} \mathrm{C}$. Then, $\operatorname{Pr}=1.27$.

The heat transfer coefficient will be:

$$
\alpha_{m i}=0.625 \frac{410.8 * 0.0121 * 1.4938}{2} \frac{1}{1+\frac{0.24}{0.0121}(1.27-1)}=0.365 \frac{\mathrm{kW}}{\mathrm{m}^{2} \mathrm{~K}}
$$

Using simple calculations, it may be demonstrated that the heat transfer coefficient depends on the gas content in the mixture, the well flow rate and the water content.

In order to calculate the pump temperature according to (1), apart from the heat-transfer coefficient, the thickness of a gas layer on the pump surface $\lambda_{\text {из }}$ must be taken into account. Further theoretical investigations of the gas layer thickness according to (1) will help in building a holistic picture of the centrifugal pump thermal conditions.

Thus, it has been shown that by making several assumptions with regard to the flow of a liquid-gas mixture in the labyrinths of a centrifugal pump, we can determine the dependence of the heat-transfer coefficient on the reservoir characteristics: flow rate, water content, gas factor and the saturation pressure.

\section{References}

[1] G. N. Alekseyev. General heat engineering. Moscow: "Vysshaya Shkola", 1980.

[2] A. A. Gareyev. On the role of the thermal behaviour of electric centrifugal pumps. "Oborudovaniye i tekhnologii dlya neftepromyslovogo kompleksa" (Equipment and Technologies for Oil Production). 2009, No. 1, pp. 23-29.

[3] A. A. Gareyev. Regarding the maximum gas content at an electric centrifugal pump inlet. "Oborudovaniye i tekhnologii dlya neftepromyslovogo kompleksa" (Equipment and Technologies for Oil Production). 2009, No. 2, pp. 21-25. 
[4] A. A. Gareyev. Regarding the thermal behaviour of electric submersible pumps. "Oborudovaniye i tekhnologii dlya neftepromyslovogo kompleksa" (Equipment and Technologies for Oil Production). 2010, No. 6, pp. 35-41.

[5] A. A. Gareyev. Regarding the gas separation coefficient at a pump inlet. "Neft'anoye khozyaistvo" (Oil Facility), 2010. No. 6, pp. 90-93.

[6] A. A. Gareyev. Regarding the thermal behaviour and thermal shock phenomenon of an electric centrifugal pump (as a matter for discussion). "Neft'anoye khozyaistvo" (Oil Facility), 2011, No. 3, pp. 122-126.

[7] A. A. Gareyev et al. Regarding electric centrifugal pump suction pressure. "Neft'anoye khozyaistvo" (Oil Facility), 2012, No. 10, pp. 128-131.

[8] A. A. Gareyev. Regarding the calculation of the gas separation coefficient at the pump inlet. "Neft'anoye khozyaistvo" (Oil Facility), 2013, No. 3, pp. 82-85.

[9] A. A. Gareyev. Salt deposition in a centrifugal pump as a result of boiling. "Inzhener Surgutneftegaza" (Surgutneftegaz Engineer) 2017, No. 11, pp. 45-50.

[10] A. A. Gareyev. Electric centrifugal pump operation practices without salt deposition. "Oborudovaniye i tekhnologii dlya neftepromyslovogo kompleksa"
(Equipment and Technologies for Oil Production). 2018, No. 3, pp. 27-31.

[11] A. A. Gareyev. Regarding the salt deposition mechanism. "Neftepromyslovoye delo" (Oilfield Engineering), 2017, No. 2, pp. 58-65.

[12] A. A. Gareyev. Regarding "self-induced relaxation oscillations" of centrifugal pump duty cycles. "Neftepromyslovoye delo" (Oilfield Engineering), "Neft'anoye khozyaistvo" (Oil Facility), 2015, No. 12, pp. $132-145$.

[13] R. Reid, J. Prausnitz, T. Sherwood. The properties of gases and liquids. "Khimiya” (Chemistry), Leningrad Division, 1982.

[14] F. F. Tsvetkov, B. A. Grigoryev. Heat-mass exchange. Moscow. MPEI (Moscow Power Engineering Institute) Publishing House, 2006.

[15] V. E. Kaschavtsev, I. T. Mischenko. Scaling during oil recovery. "Orbita", 2004.

[16] D. A. Labuntsov. Physical fundamentals of power engineering. MPEI (Moscow Power Engineering Institute) Publishing House, 2000, p. 388. 